\title{
Isoform-specific NF1 mRNA levels correlate with disease severity in Neurofibromatosis type 1
}

\author{
Antonia Assunto', Ursula Ferrara', Alessandro De Luca², Claudia Pivonello³, Lisa Lombardo', Annapina Piscitelli', \\ Cristina Tortora ${ }^{4}$, Valentina Pinna', Paola Daniele ${ }^{1}$, Rosario Pivonello ${ }^{3}$, Maria Giovanna Russo ${ }^{5}$, \\ Giuseppe Limongelli ${ }^{5}$, Annamaria Colao ${ }^{3}$, Marco Tartaglia ${ }^{6}$, Pietro Strisciuglio ${ }^{1}$ and Daniela Melis ${ }^{1 *}$ (D)
}

\begin{abstract}
Background: Neurofibromatosis type 1 (NF1) is characterized by an extreme clinical variability both within and between families that cannot be explained solely by the nature of the pathogenic NF1 gene mutations. A proposed model hypothesizes that variation in the levels of protein isoforms generated via alternative transcript processing acts as modifier and contributes to phenotypic variability.

Results: Here we used real-time quantitative PCR to investigate the levels of two major NF1 mRNA isoforms encoding proteins differing in their ability to control RAS signaling (isoforms I and II) in the peripheral blood leukocytes of 138 clinically well-characterized NF1 patients and 138 aged-matched healthy controls. As expected, expression analysis showed that NF1 isoforms I and II levels were significantly lower in patients than controls. Notably, these differences were more evident when patients were stratified according to the severity of phenotype. Moreover, a correlation was identified when comparing the levels of isoform I mRNA and the severity of NF1 features, with statistically significant lower levels associated with a severe phenotype (i.e., occurrence of learning disability/intellectual disability, optic gliomas and/or other neoplasias, and/or cerebrovascular disease) as well as in patients with cognitive impairment.

Conclusions: The present findings provide preliminary evidence for a role of circuits controlling NF1 transcript processing in modulating NF1 expressivity, and document an association between the levels of neurofibromin isoform I mRNA and the severity of phenotype and cognitive impairment in NF1.
\end{abstract}

Keywords: NF1, Neurofibromatosis type 1, Alternative splicing, Gene expression, mRNA isoforms, Phenotypic expressivity, Clinical variability

\section{Background}

Alternative splicing, the mechanism by which eukaryotic cells generate multiple RNAs from a single transcript, maximizes genome plasticity and versatility by promoting diversification of protein function and its spatiotemporal control [1-3]. In humans, as many as $92-94 \%$ of multiexon genes are predicted to undergo alternative splicing [4]. This process is important in the control of developmental programs and cell physiology, as well as in the pathogenesis

\footnotetext{
* Correspondence: daniela.melis@unina.it

${ }^{1}$ Department of Translational Medical Science, Section of Pediatrics, Federico

II University, Via Sergio Pansini, 5, 80131 Naples, Italy

Full list of author information is available at the end of the article
}

and progression of human diseases [5]. It has been proposed that alternative splicing contributes to the clinical variability of Mendelian disorders by altering either the level of correctly spliced RNA pools or the ratio of different mRNA isoforms that result from transcript processing [6].

Neurofibromatosis 1 (NF1 [MIM: 162200]) is the most common non-chromosomal disorder affecting development and predisposing to cancer (approx. 1:2000-3000 live births) $[7,8]$. It is transmitted as an autosomal dominant trait, and is caused by germline loss-of-function mutations in the NF1 gene, which encodes neurofibromin, a GTPase negatively controlling RAS signaling [9]. Major features of NF1 include café-au-lait macules, skinfold freckling, and

(C) The Author(s). 2019 Open Access This article is distributed under the terms of the Creative Commons Attribution 4.0 International License (http://creativecommons.org/licenses/by/4.0/), which permits unrestricted use, distribution, and 
Lisch nodules of the iris, cutaneous and/or subcutaneous neurofibromas, variable learning disability/cognitive deficit (LD/CD), skeletal defects, and an increased risk for certain malignancies [10]. The neoplastic risk is related to functional loss of the GTPase activity of neurofibromin due to somatic hits involving NF1, according to the Knudson's model, causing cell autonomous, and sustained activation of the Ras-mitogen-activated protein kinases (MAPK) pathway.

While NF1 is characterized by complete penetrance, variable expressivity is observed, with marked clinical variability even within families [11]. Phenotypic studies of large cohorts suggest that the type of mutation in the NF1 gene generally does not correlate with the observed phenotypic variation $[12,13]$. Exceptions are the constitutional NF1 microdeletions [14] and missense variants affecting codons 844-848, which are associated with a more severe presentation [15], and the missense variants at codon 1809 [16, 17] and the 3-bp in-frame deletion, c.2970_2972del (p.Met992del), which conversely, are associated with a mild, mainly cutaneous, clinical presentation $[18,19]$. Overall, the genotype-phenotype correlations identified so far have been reported to explain only a small amount of the extent of clinical variability characterizing the NF1 population [15, 19], and other factors, including stocastic events (e.g., second hits), and the genetic background (variation in modifier genes) are expected to contribute to a much larger fraction of the NF1 phenotipic variability [11]. The evidence that modifier genes contribute to the phenotypic expression of NF1 is strongly supported by familial studies [11, 13, 20, 21], which show that, independently by the NF1 mutation, the grade of phenotypic concordance between members of the same family correlates with the genetic background, and that the relative contribution of the genetic background varies depending from the feature in question $[11,20]$. Further evidence that genetic modifiers are major contributor to the variable expression of NF1 comes from studies on animal models showing that $\mathrm{Nf1}^{+-}$mice strains have differences in phenotype severity with regards to the learning and behavioral aspects of the phenotype, as well as in the susceptibility to form astrocytomas [22-25]. Notably, by assessing Nf1 mRNA levels in these models, it was also shown that trans-acting events modulate the phenotypic expression by impacting $N f 1$ gene expression [26].

NF1 is a large gene and its pre-mRNA undergoes alternative splicing. Several alternative exons that do not alter the reading frame of the gene have been identified, including 9a/9br, 10a-2, and 48a [6]. Of particular interest is exon 23a, which lies within the GAP-related domain (GRD) of neurofibromin, and is predominantly retained in most tissues, but specifically skipped in central nervous system neurons in humans $[27,28]$. Of note, the two neurofibromin isoforms including/lacking the short amino acid stretch encoded by this exon differ in their ability to control Ras function [27, 28]. Isoform I, which lacks exon 23a, has ten times higher Ras-GAP activity than isoform II, in which exon 23a is retained. Biological importance of this exon during development has consistently been underlined by the observation that the mouse model in which exon 23a is constitutively deleted has a learning phenotype [24]. These considerations suggest an intriguing hypothesis in which changes in the levels of protein isoforms generated via alternative transcript processing, including alternative splicing, acts as genetic modifier in NF1 patients.

In the present study, we analyzed the levels of neurofibromin isoform I and II in circulating leukocytes of a cohort of genetically and clinically characterized NF1 patients stratified according to the severity of the phenotype, and correlated their expression levels with disease severity to assess whether alternative splicing may contribute to the variable expression characterizing NF1.

\section{Patients and methods}

\section{Aim, design and setting of the study}

One hundred and thirty eight individuals diagnosed with NF1 according to National Institutes of Health criteria were enrolled into the study at the Department of Translational Medicine, Federico II University of Naples, Pediatric Section, after the study protocol was discussed with each patient (or legal tutor) and an informed consent was signed. Patients' clinical data were obtained from medical records over the past 20 years.

Collected clinical information included family history, and presence or absence of cafè-au-lait macules (CALMs), intertriginous skin freckling, Lisch nodules, cardiovascular malformations, skeletal malformations, endocrine system involvement, developmental delay (DD)/intellectual disability (ID), cerebrovascular malformations, cutaneous and subcutaneous neurofibromas (NFs), plexiform neurofibromas (PNFs), spinal neurofibromas, optic pathway gliomas (OPGs), and occurrence of other neoplasms (e.g., central nervous system gliomas, malignant peripheral nerve sheath tumors -MPNSTs-, juvenile myelomonocytic leukemia, rhabdomyosarcoma, phaeochromocytoma, gastrointestinal stromal tumours, juvenile xanthogranuloma, and lipoma). On the basis of clinical features, patients were divided into three groups according to the severity of the phenotype using the classification proposed by Riccardi [29]. The levels of NF1 mRNA isoforms were investigated in peripheral blood leukocytes of patients and sex- and age-matched controls. All patients were screened for NF1 and SPRED1 mutations by parallel sequencing of the whole coding region and intronic stretches flanking splice sites $( \pm 10 \mathrm{bp})$. Structural rearrangements were assessed by MLPA analysis using the MRC-Holland P295 probe set.

A comprehensive NF1 database with clinical and genetic data was built up. Genotype-phenotype correlations 
were investigated for each common clinical abnormality individually and for three groups of severity of disease.

\section{Study population}

The study cohort included 17 families segregating the trait $(12.31 \%)$ and 121 sporadic cases $(87.69 \%)$ resulting from de novo mutations. Sixty-eight patients were males and 70 were females. The average age at time of diagnosis was 6.7 years (range $0.3-45$ years), whereas the avarage age at observation was 16.4 years (range $0.60-55.90$ years). Forty patients were children (aged between 0.6 and 11 years), 34 were in pubertal age (aged between 12 and 16), and 64 were adults (aged between 17 and 55.9).

Patients presenting with CALMs, axillary freckling, Lisch nodules, dermal and/or nodular neurofibromas, and non-progressive scoliosis were classified as "mild", those presenting with plexiform neurofibromas, skeletal malformation, precocious or progressive scoliosis were classified as "moderate", and patients with LD/CD, optic glioma and/or other neoplasms, and/or cerebrovascular disease were classified as "severe". According to this stratification, 49 patients were classified as having a mild phenotype, 43 with as moderate phenotype and 46 as showing a severe phenotype. Demographic and clinical characteristics of the whole study cohort and subcohorts are reported in Table 1. A pathogenic or likely pathogenic NF1 variant was found in 106/138 (76.8\%) of the cases (see Additional file 1: Table S1 for details).

\section{Expression studies}

Relative expression of NF1 isoforms I and II was assessed using TaqMan-based real-time quantitative PCR (RT-qPCR) assays, according to manufacturer's recommendations (Thermo Fisher Scientific, Waltham,
MA, USA). These assays were specific for NF1 isoforms I and for isoform I+ II, respectively. The expression value of isoform II was reported either as the sum of the expression value of both isoforms I and II pools and as isoform II data obtained subtracting the expression value of isoform I from the sum of the expression value of both isoforms I and II pools. Primers for RT-qPCR were purchased as assay-on demand (Thermo Fisher Scientific). Peripheral blood mononuclear cell samples obtained from patients and healthy controls were prepared from EDTA-anticoagulated blood by Ficoll-Hypaque density gradient centrifugation. Total RNA was extracted using TRIzol (Invitrogen Corporation, Carlsbad, CA, USA), according to the manufacturer's instructions. Reverse transcription of first-strand cDNA was performed using oligo dT and the High-Capacity cDNA Archive Kit (Thermo Fisher Scientific), starting from $500 \mathrm{ng}$ of RNA as a template. Beta-2-microglobulin (B2M) housekeeping gene was used as internal control. NF1 and $B 2 M$ mRNA pools were amplified from $100 \mathrm{ng}$ of cDNA using the TaqMan Gene Expression PCR Master Mix (Thermo Fisher Scientific), according to the manufacturer's instructions. Samples were run in duplicate, and mRNA levels were determined by comparing the expression of the two NF1 isoforms with that of $B 2 M$ internal control. Real-time qPCR was performed with an ABI 7900 Real-Time PCR instrument (Thermo Fisher Scientific). The data were analyzed with the SDS relative quantification software version 1.2.1 (Thermo Fisher Scientific). Relative quantification was performed using the Pfaffl method [30]. To ensure reliability of the data, 20 randomly selected patients were reanalyzed by RTqPCR after one-year interval, proving high reproducibility of the data.

Table 1 Demografic and clinical characteristics of the 138 patients with NF1 included in the study

\begin{tabular}{|c|c|c|c|c|}
\hline Feature & Mild phenotype $(n=49)$ & Moderate $(n=43)$ & Severe phenotype $(n=46)$ & Whole cohort $(n=138)$ \\
\hline Mean age (average) & $\begin{array}{l}21.1 \text { years } \\
(2.2-55.9 \text { years })\end{array}$ & $\begin{array}{l}14.6 \text { years } \\
\text { (1.2-36.4 years) }\end{array}$ & $\begin{array}{l}12.9 \text { years* } \\
(0.6-53.5 \text { years })\end{array}$ & $\begin{array}{l}16.4 \text { years } \\
(0.60-55.90 \text { years })\end{array}$ \\
\hline No mutation & $N=13$ & $N=8$ & $N=10$ & $N=30$ \\
\hline Gender & $M=19 ; F=30$ & $M=27 ; F=16$ & $M=22 ; F=24$ & $M=68 ; F=70$ \\
\hline CALMs & 49 (100\%) & $43(100 \%)$ & $46(100 \%)$ & 138 \\
\hline Lisch nodules & $18(36.8 \%)$ & $20(46,5 \%)$ & $25(54.4 \%)$ & $63(45,6 \%)$ \\
\hline Axillary and/or inguinal freckling & $37(75.5 \%)$ & $37(86.0 \%)$ & $33(71.8 \%)$ & $107(77,5 \%)$ \\
\hline Plexiform neurofibroma & $0(0.0 \%)$ & $9(20.9 \%)$ & $9(19 / 6 \%)$ & $18(13 \%)$ \\
\hline Mild non-progressive scoliosis & $21(42.9 \%)$ & $20(46.5 \%)$ & NA & $41(29,7 \%)$ \\
\hline Progressive scoliosis & $0(0.0 \%)$ & $18(41.8 \%)$ & $25(54.4 \%)$ & $43(31,1 \%)$ \\
\hline Heart involvement & $7(14.3 \%)$ & 9 (20.9\%) & $12(26.1 \%)$ & $28(20,2 \%)$ \\
\hline OPG & $0(0.0 \%)$ & $0(0.0 \%)$ & $27(58.7 \%)$ & $27(19,5 \%)$ \\
\hline Other tumors & $0(0.0 \%)$ & $0(0.0 \%)$ & $17(37.0 \%)$ & $17(12,3 \%)$ \\
\hline Development delay and/or cognitive deficit & $0(0.0 \%)$ & 0 & $28(60.9 \%)$ & $28(20,2 \%)$ \\
\hline
\end{tabular}

*for 45 living subjects; $F$ females, $M$ males, $N A$ not available 


\section{Statistical analysis}

Pearson's correlation coefficients were used for the association studies. Group means (NF1 isoforms I and II expression levels) were compared between groups by t-test for unpaired data. All statistical analyses were undertaken using the Statistical Package for the Social Sciences Software (SPSS) version 22 (IBM Corp., Armonk, NY, USA). A $p$-value less than 0.05 was considered significant. For statistical analysis comparing different groups of patients (namely patients with mild, moderate and severe phenotye), exclusively data from patients with diagnosis confirmed by molecular analysis were included.

\section{Results}

Expression levels of NF1 mRNA isoforms I and II were examined in peripheral blood leukocytes of 138 NF1 patients and compared with those of 138 population-, ageand sex-matched healthy controls. The expression value of isoform II was reported either as the sum of the expression value of both isoforms I and II pools and as isoform II data obtained subtracting the expression value of isoform I from the sum of the expression value of both isoforms I and II pools. Levels of NF1 isoforms I, isoform (I + II) and isoform II are reported in Table 2.

\section{Data analysis of isoform (I + II) provided results and statistical significance consistent with isoform II assessment}

As expected, the analysis showed that the expression levels of both isoforms I and II were significantly lower in patients compared to controls (isoform I: $p=5.47 \mathrm{E}$ 06; isoform II: $p=0.0004)$. These differences remained significant when comparisons were made between healthy controls and patients subdivided according to disease severity (Table 2). Assessment of a possible correlation between the expression levels of NF1 isoforms and the severity of disease documented a significant association between the expression level of isoform I and disease severity (linear association 6.2, $p=0.01$ ). In particular, the expression level of isoform I was inversely correlated with disease severity either considering the entire cohort (Pearson $\mathrm{r}=-0.247, p=0.012$ ), or when considering exclusively pediatric patients (Pearson $r=-$ 0.427, $p=0.01$ ). Subsequently, we specifically analyzed the expression level of NF1 isoform I in severe cases respect to cases with moderate and mild phenotypes. Analysis confirmed that the expression level of isoform I was consistently reduced in the former. Similar results were obtained either considering the whole cohort $(p=0.002)$ or when only pediatric patients were included in the analysis $(p=0.002)$ (Fig. 1). Notably, the isoform II/isoform I ratio was higher in patients with severe phenotype althought it did not reach statistical significance (Table 2), suggesting a possible contribution of altered transcript processing to phenotypic expressivity. In order to evaluate the reproducibility of the data, the assays directed to analyze isoform 1 and isoform II levels were replicated in an unselected subgroup of patients randomly choosen after 2 years (Fig. 2).

To assess a possible differential contribution of specific clinical features defining the severe phenotype with the observed association, the levels of NF1 mRNA isoforms were compared between groups taking into account LD/ $\mathrm{CD}$, neoplasias and cerebrovascular disease. Remarkably, patients with LD/CD showed significantly lower levels of isoform I than patients without $\operatorname{LD} / C D(p=0.038)$. Importantly, this association remained significant after excluding from the analysis the affected subjects with NF1 microdeletion $(p=0.039)$ or when only pediatric patients were considered $(p=0.02)$. This observation is relevant since by definition, patients with NF1 microdeletion are haploinsufficient and display higher prevalence of LD/ $\mathrm{CD}$ respect to the general NF1 population. By contrast, no significant association was found between NF1 isoform expression and presence of neoplasias $(P=0.22)$ or cerebrovascular disease $(P=0.98)$.

To check whether the type of mutation influenced the observed association, we compared the prevalence of truncating and missense mutations, as well as the localization of mutations within the GRD (exons 21-27) in patients with severe phenotype and in those with moderate and mild phenotypes (Fig. 3). Comparative analysis showed no statistically significant association between the severity of phenotype and either the type of mutation or localization within the GRD $(p>0.05)$. To rule out the impact of sequence variation on PCR cynetics and probe binding, all patients were reanalyzed and the occurrence of variation located within the stretches relevant for probe/primer binding of the two TaqMan assays was excluded. Only exceptions were represented by two variants, c.4537C $>\mathrm{T}$ and c.7778delA, which mapped closely to the annealing site of the TaqMan assay for isoform 1 and for isoform $1 / 2$, respectively. However, patients \#13 (with mild phenotype) and \#22 (with severe phenotype), despite being both heterozygous for c.4537C > T variant, showed opposite expression levels of isoform 1, under and above the average, respectively. As much as regard variant c.7778delA, case \#32 (severe phenotype), who was heterozygous for this variant, showed an expression level of isoform II below the average, but the significance of results did not change after excluding this case from the analysis ( $p=$ 0.02 ). Healthy controls were not sequenced, therefore we cannot exclude the presence of rare variants occurring within the genomic stretches annealing with the TaqMan primers/probes among these subjects. However, these genomic regions do not contain common variants occurring in human populations, as reported in the 
Table 2 Comparative analysis of the expression levels of NF1 isoforms I and II in peripheral blood leukocytes of NF1 patients and healthy controls stratified for the severity of the phenotype, and for the presence or absence of LD/MR. Mean value \pm SE are reported

\begin{tabular}{|c|c|c|c|}
\hline & NF1 patients & Healthy controls & $P$ value \\
\hline Total & 138 & 138 & \\
\hline Isoform I & $0.00066 \pm 0.0001$ & $0.0012 \pm 0.0007$ & 5.47E-06 \\
\hline Isoform || & $0.0024 \pm 0.001$ & $0.01 \pm 0.004$ & 0.0004 \\
\hline Isoform II + I & $0.0029 \pm 0.0002$ & $0.019 \pm 0.003$ & 0.0004 \\
\hline \multirow[t]{2}{*}{ Isoform II/I } & $4.39 \pm 1.9$ & $4.05 \pm 1.3$ & 0.5 \\
\hline & Patients with severe phenotype & Patients with mild phenotype & \\
\hline Total & 36 & 36 & \\
\hline Isoform I & $0.0004 \pm 0.0001$ & $0.0008 \pm 0.0001$ & 0.002 \\
\hline Isoform || & $0.0017 \pm 0.0018$ & $0.0025 \pm 0.001$ & 0.09 \\
\hline |soform || + | & $0.0017 \pm 0.001$ & $0.0029 \pm 0.0002$ & 0.6 \\
\hline \multirow[t]{2}{*}{ |soform ||/I } & $5.93 \pm 1.7$ & $3.92 \pm 1.8$ & 0.14 \\
\hline & Patients with LD/MR & Patients without LD/MR & \\
\hline Total & 26 & 45 & \\
\hline Isoform I & $0.0004 \pm 0.00009$ & $0.0007 \pm 0.0002$ & 0.038 \\
\hline Isoform || & $0.0015 \pm 0.0005$ & $0.0024 \pm 0.0008$ & 0.11 \\
\hline |soform II + | & $0.0019 \pm 0.0003$ & $0.0029 \pm 0.0005$ & 0.09 \\
\hline \multirow[t]{2}{*}{ |soform ||/I } & $4.92 \pm 1.7$ & $4.2 \pm 1.8$ & 0.60 \\
\hline & Pediatric patients with LD/MR & Pediatric patients without LD/MR & \\
\hline Total & 22 & 31 & \\
\hline Isoform I & $0.0001 \pm 0.00008$ & $0.0007 \pm 0.0002$ & 0.02 \\
\hline Isoform || & $0.0014 \pm 0.0004$ & $0.0026 \pm 0.001$ & 0.10 \\
\hline |soform || + | & $0.0015 \pm 0.0003$ & $0.0029 \pm 0.001$ & 0.06 \\
\hline Isoform ||/I & $4 \pm 1.4$ & $3.72 \pm 1.6$ & 0.88 \\
\hline
\end{tabular}

$L D / C D$ learning disability/cognitive deficit

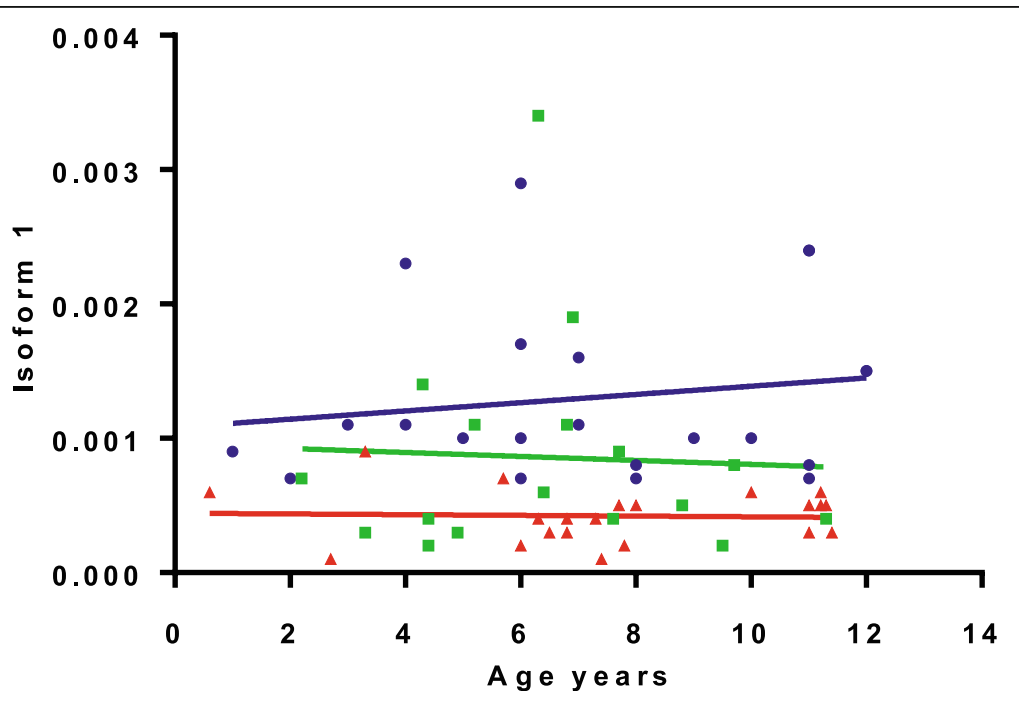

Fig. 1 Comparison of NF1 mRNA levels according to specific age between children with mild and (Green square) severe (Red triangle) phenotype and controls (Blue circle) 


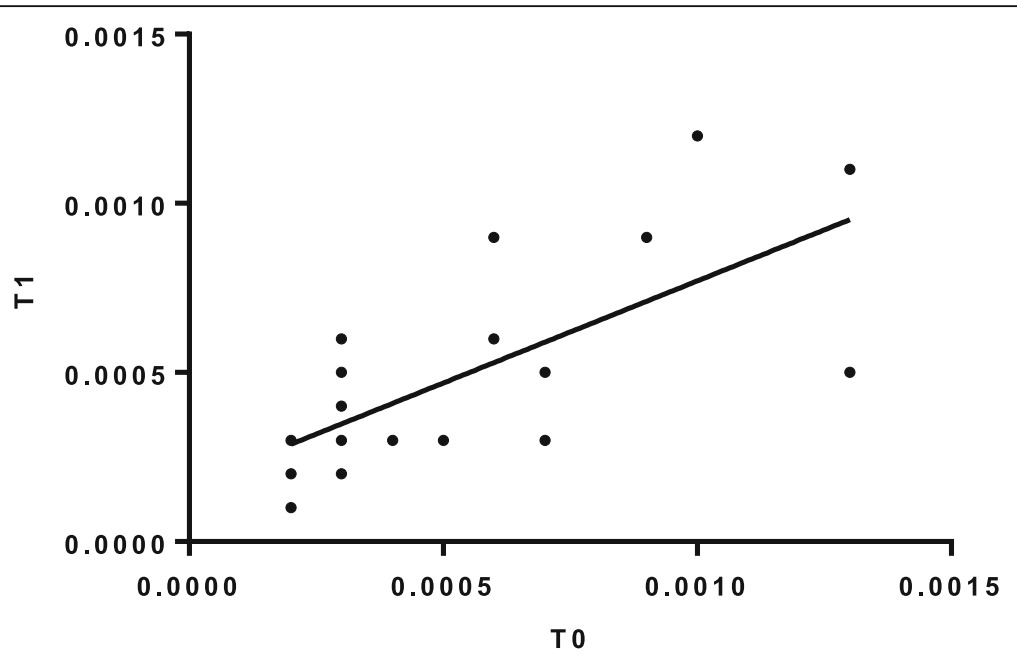

Fig. 2 Results of the assays directed to analyze isoform 1 levels which were replicated in an unselected subgroup of patients randomly choose after 2 years

Ensembl genome browser (https://www.ensembl.org/ Homo_sapiens/Info/Index) or the ExAC database (http://exac.broadinstitute.org/).

\section{Discussion}

In this study, we tested the hypothesis of a contribution of processes controlling/mediating NF1 transcript processing to the variable phenotypic expressivity characterizing NF1 by analyzing the level of expression of the two main mRNA isoforms of the gene, which encode proteins that differ in their abilities to control Ras signaling.

NF1 is the result of loss-of-function mutations in the NF1 gene. In this study, more than $75 \%$ of the mutations identified lead to the introduction of a premature termination codon in the coding sequence, which is in line with previous findings $[12,31]$. Because of the nonsensemediated RNA decay mechanism, many of these mutations are expected to lead to a reduction in the level of expression of the NF1 transcript [32]. Consistently, we found that NF1 mRNA was expressed at significantly lower levels in the peripheral blood leukocytes of NF1 patients than in healthy subjects, independently from the protein isoform that was considered and from the severity of the phenotype. Further data analysis showed that the neurofibromin isoform with higher GAP activity, isoform I, was expressed at significantly lower levels in subjects with severe phenotype respect to affected subjects with mild/moderate phenotypes, independently of the age. Moreover, when patients were compared based on the presence vs absence of $\mathrm{LD} / \mathrm{CD}$, cerebral tumors and cerebrovascular disease, analyses showed that a lower expression level of isoform I was significantly associated with occurrence of LD/CD. Such specific association is of particular relevance since isoform I is predominantly expressed in central nervous system neurons [33], and the finding that in mice, constitutional homozygous

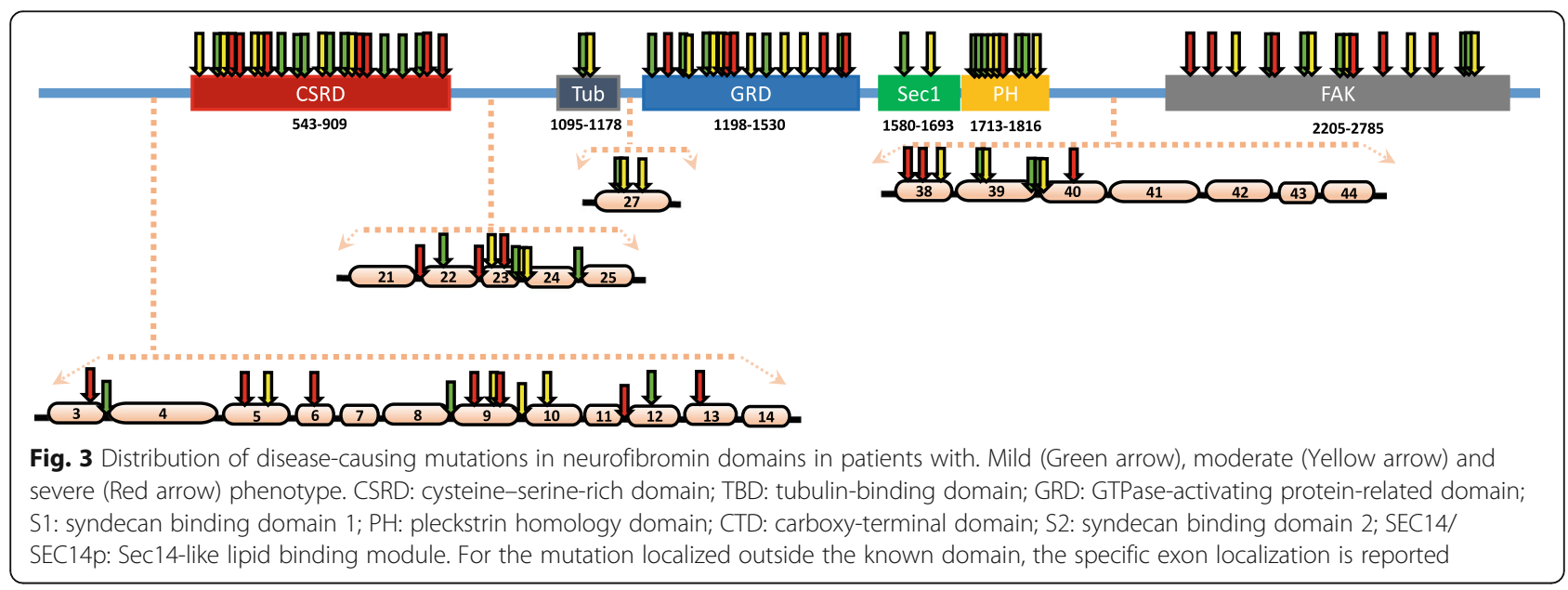


deletion of exon 23a (i.e., loss of Nf1 mRNA isoform 1 expression in all tissues) is viable, do not affect development or cause cancer predisposition but results in spatial learning and memory defects [24, 25]. Consistent with the findings collected in mice, we did not observe any significant difference in the expression of the two NF1 isoforms in relation to tumor formation or vascular disease. This is in line with the consideration that cell transformation is expected to require complete loss/ functional inactivation of neurofibromin, which is more likely to depend upon somatic hits affecting the wildtype allele rather than events causing aberrant transcript processing. This also applies to vasculopathy and other NF1-related features, including café-au-lait spots or tibial pseudarthrosis, in which the somatic second hit has been detected in the pathologic tissue [34-36]. On the opposite, learning disability phenotypes are more thought to be related to neurofibromin haploinsufficiency and therefore could be more influenced by the balance between the expression of the two neurofibromin isoforms in the brain $[6,24,25]$. It is important to underline that the association between reduced isoform I expression and learing phenotype was still present when only subjects in pediatric age were considered. This is an extremely significant observation since the LD/CD phenotype has profound implications for the management of the disease, especially in early age, and the identification of predictive markers might be useful for the clinical management of these patients [37]. Inclusion/skipping of NF1 exon 23a is a tightly regulated process during development, depending on the cellular context. This alternative splicing event is under complex control with many regulatory factors involved. Like other alternative exons, also NF1 exon 23a is characterized by the presence of weak consensus sequences surrounding the exon that are not readily recognized by the splicing machinery [6]. Although not identified yet, it is possible that variation involving cis- and/or trans-acting elements controlling/participating in exon 23a retention/ skipping could result in the failure of proper NF1 transcript processing, leading to an imbalance in the distribution of the type I and type II isoforms and this in turn to phenotypic consequences in NF1 patients.

It has been widely demonstrated that dysregulation of posttranscriptional regulation, including alternative splicing, results in defective neuronal differentiation and/or synaptic connections, leading to neurodevelopmental and psychiatric disorders [38, 39]. Different genetic and chemical approaches to target components of the spliceosome to correct splicing defects have been investigated in pathological conditions including cancer and neurologic disorders. Advancements in the understanding of NF1-specific defects caused by mis-regulation of alternative splicing might increase the development of specific therapeutic options in NF1 [40-42].

\section{Conclusions}

The present findings provide a first evidence for a role of circuits controlling NF1 transcript processing in modulating phenotypic expressivity in NF1, and document an association between the levels of neurofibromin isoform I mRNA and the severity of phenotype and cognitive impairment. The identification of this association between specific NF1 expression pattern and phenotype variability is remarkable and deserves further exploration. Expression studies at the protein level and in relevant tissues/cell lineages are required steps to validate the present findings.

\section{Supplementary information}

Supplementary information accompanies this paper at https://doi.org/10. 1186/s13023-019-1223-1

Additional file 1: Table S1. List of NF1 mutations identified in individuals with MILD NF1 phenotype.

\section{Abbreviations}

CALMs: Cafè-au-lait macules; GRD: GAP-Related domain; LD/CD: Learning disabilities/cognitive deficit; MAPK: Ras-mitogen-activated protein kinases; MPNSTs: Malignant peripheral nerve sheath tumors; NF1: Neurofibromatosis 1; NFs: Subcutaneous neurofibromas; OPGs: Optic pathway gliomas; PNFs: Plexiform neurofibromas

\section{Acknowledgments}

The authors wish to thank the patients and families who participated in this research. We would like to thank Rosaria Tuzzi, Stefania Cavone and Angela Alberico for expert technical assistance.

\section{Authors' contributions}

A.A., C.P., L.L., A.P. performed realtime analysis, ADL, V.P., P.D. performed DNA molecular analysis, U.F., C.T., D. M followed-up the patients and recorded specific clinical features, MGR, GL, RP, AC were involved in clinical follow-up of the patients, DM wrote the manuscript, ADL, RP, AC, MT, PS critically reviewed the manuscript. All authors read and approved the final manuscript.

\section{Funding}

This work was supported with grant support from the Italian Ministry of Health (RC 2018 and 2019 to ADL and MT) and AIRC (IG 21614) to MT.

Availability of data and materials

The datasets used and/or analysed during the current study are available from the corresponding author on reasonable request.

Ethics approval and consent to participate

Study was approved by Ethics Committee with comunication number 1893/ 18, study protocol number 315/18 "Comitato Etico Università Federico II di Napoli, Prof Claudio Buccelli".

\section{Consent for publication}

Manuscript does not include use of any animal or human data or tissue and does not contain data from any individual person.

\section{Competing interests}

The authors declare that there is no conflict. The authors declare that they have no competing interests".

\section{Author details}

${ }^{1}$ Department of Translational Medical Science, Section of Pediatrics, Federico II University, Via Sergio Pansini, 5, 80131 Naples, Italy. ${ }^{2}$ IRCCS Casa Sollievo della Sofferenza, Molecular Genetics Unit, San Giovanni Rotondo, Foggia, Italy. ${ }^{3}$ Dipartimento di Medicina Clinica ed Endocrinologia, Università degli Studi di Napoli, "Federico II", Naples, Italy. ${ }^{4}$ Department of Molecular 
Medicine and Medical Biotechnology Federico II University, Naples, Italy. 5Università della Campania "Luigi Vanvitelli", AORN Colli, Ospedale Monaldi, Naples, Italy. ${ }^{6}$ Genetics and Rare Diseases Research Division, Ospedale Pediatrico Bambino Gesù, Rome, Italy.

\section{Received: 8 June 2019 Accepted: 9 October 2019}

\section{Published online: 15 November 2019}

\section{References}

1. Paronetto MP, Passacantilli I, Sette C. Alternative splicing and cell survival: from tissue homeostasis to disease. Cell Death Differ. 2016;23(12):1919-29.

2. lijima T, Hidaka C, lijima Y. Spatio-temporal regulations and functions of neuronal alternative RNA splicing in developing and adult brains. Neurosci Res. 2016;109:1-8.

3. Marden JH. Quantitative and evolutionary biology of alternative splicing: how changing the mix of alternative transcripts affects phenotypic plasticity and reaction norms. Heredity. 2008;100(2):111-20.

4. Pan Q, Shai O, Lee LJ, Frey BJ, Blencowe BJ. Deep surveying of alternative splicing complexity in the human transcriptome by high-throughput sequencing. Nat Genet. 2008:40(12):1413-5. https://doi.org/10.1038/ng.259 Epub 2008 Nov 2.

5. Wang GS, Cooper TA. Splicing in disease: disruption of the splicing code and the decoding machinery. Nat Rev Genet. 2007;8(10):749-61 Epub 2007 Aug 29.Review.

6. Barron VA, Lou H. Alternative splicing of the neurofibromatosis type I premRNA. Biosci Rep. 2012;32(2):131-8. https://doi.org/10.1042/BSR20110060 Review

7. Evans DG, Howard E, Giblin C, et al. Birth incidence and prevalence of tumor-prone syndromes: estimates from a UK family genetic register service. Am J Med Genet A. 2010;152A:327-32.

8. Uusitalo E, Leppavirta J, Koffert A, et al. Incidence and mortality of neurofibromatosis: a total population study in Finland. J Invest Dermatol. 2015;135:904-6.

9. Trovó-Marqui AB, Tajara EH. Neurofibromin: a general outlook. Clin Genet. 2006;70(1):1-13.

10. Peltonen, S., And Pöyho "nen M. Clinical diagnosis and atypical forms of NF1. In M. Upadhyaya and D.N. Cooper, eds. Molecular and cellular biology, Springer-Verlag Berlin, 2012. pp. 17-30.

11. Pasmant E, Vidaud M, Vidaud D, Wolkenstein P. Neurofibromatosis type 1: from genotype to phenotype. J Med Genet. 2012 Aug;49(8):483-9. https:// doi.org/10.1136/jmedgenet-2012-100978.

12. De Luca A, Schirinzi A, Buccino A, Bottillo I, Sinibaldi L, Torrente I, Ciavarella A, Dottorini T, Porciello R, Giustini S, Calvieri S, Dallapiccola B. Novel and recurrent mutations in the NF1 gene in Italian patients with neurofibromatosis type 1. Hum Mutat. 2004 Jun;23(6):629

13. Sabbagh A, Pasmant E, Imbard A, et al. NF1 molecular characterization and neurofi- bromatosis type I genotype-phenotype correlation: the French experience. Hum Mutat. 2013:34:1510-8.

14. Kehrer-Sawatzki H, Mautner VF, Cooper DN. Emerging genotype-phenotype relationships in patients with large NF1 deletions. Hum Genet. 2017;136(4): 349-76. https://doi.org/10.1007/s00439-017-1766-y Epub 2017 Feb 17.

15. Koczkowska M, Chen Y, Callens T, et al. Genotype-Phenotype Correlation in NF1: Evidence for a More Severe Phenotype Associated with Missense Mutations Affecting NF1 Codons 844-848. Am J Hum Genet. 2018;102:69-87.

16. Pinna V, Lanari V, Daniele P, Consoli F, Agolini E, Margiotti K, Bottillo I, Torrente I, Bruselles A, Fusilli C, Ficcadenti A, Bargiacchi S, Trevisson E, Forzan M, Giustini S, Leoni C, Zampino G, Digilio MC, Dallapiccola B, Clementi M, Tartaglia M, De Luca A. P.Arg1809Cys substitution in neurofibromin is associated with a distinctive NF1 phenotype without neurofibromas. Eur J Hum Genet. 2015;23(8):1068-71. https://doi.org/10. 1038/ejhg.2014.243 Epub 2014 Nov 5.

17. Rojnueangnit K, Xie J, Gomes A, Sharp A, Callens T, Chen Y, Liu Y, et al. High incidence of Noonan syndrome features including short stature and pulmonic stenosis in patients carrying NF1 missense mutations affecting p. Arg1809: genotype-phenotype correlation. Hum Mutat. 2015;36(11):1052-63. https://doi.org/10.1002/humu.22832 Epub 2015 Aug 21.

18. Upadhyaya M, Huson SM, Davies M, Thomas N, Chuzhanova N, Giovannini S, Evans DG, Howard E, Kerr B, Griffiths S, Consoli C, Side L, Adams D, Pierpont M, Hachen R, Barnicoat A, Li H, Wallace P, Van Biervliet JP, Stevenson D, Viskochil D, Baralle D, Haan E, Riccardi V, Turnpenny P, Lazaro $C$, Messiaen L. An absence of cutaneous neurofibromas associated with a 3- bp inframe deletion in exon 17 of the NF1 gene (c.2970-2972 delAAT): evidence of a clinically significant NF1 genotype-phenotype correlation. Am J Hum Genet. 2007;80(1):140-51 Epub 2006 Dec 8.

19. Koczkowska M, Callens T, Gomes A, et al. Expanding the clinical phenotype of individuals with a 3-bp in-frame deletion of the NF1 gene (c.2970_ 2972del): an update of genotype-phenotype correlation. Genet Med. 2019; 21(4):867-76. https://doi.org/10.1038/s41436-018-0269-0 Epub 2018 Sep 7.

20. Easton DF, Ponder MA, Huson SM, Ponder BA. An analysis of variation in expression of neurofibromatosis (NF) type 1 (NF1): evidence for modifying genes. Am J Hum Genet. 1993 Aug;53(2):305-13.

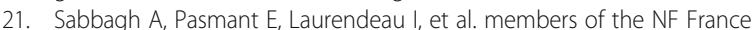
Network. Unravelling the genetic basis of variable clinical expression in neurofibromatosis 1. Hum Mol Genet. 2009:18:2768-78.

22. Reilly KM, Loisel DA, Bronson RT, McLaughlin ME, Jacks T. Nf1;Trp53 mutant mice develop glioblastoma with evidence of strain-specific effects. Nat Genet. 2000 Sep;26(1):109-13.

23. Reilly KM, Tuskan RG, Christy E, Loisel DA, Ledger J, Bronson RT, Smith CD, Tsang S, Munroe DJ, Jacks T. Susceptibility to astrocytoma in mice mutant for Nf1 and Trp53 is linked to chromosome 11 and subject to epigenetic effects. Proc Natl Acad Sci U S A. 2004;101(35):13008-13.

24. Costa RM, Yang T, Huynh DP, Pulst SM, Viskochil DH, Silva AJ, Brannan Cl. Learning deficits, but normal development and tumor predisposition, in mice lacking exon 23a of Nf1. Nat Genet. 2001;27(4):399-405.

25. Costa RM, Federov NB, Kogan JH, Murphy GG, Stern J, Ohno M, Kucherlapati R, Jacks T, Silva AJ. Mechanism for the learning deficits in a mouse model of neurofibromatosis type 1. Nature. 2002;415(6871): 526-30 Epub 2002 Jan 16.

26. Hawes JJ, Tuskan RG, Reilly KM. Nf1 expression is dependent on strain background: implications for tumor suppressor haploinsufficiency studies. Neurogenetics. 2007:8:121-30.

27. Uchida T, Matozaki T, Suzuki T, Matsuda K, Wada K, Nakano O, Konda Y, Nishisaki H, Nagao M, Sakamoto C, et al. Expression of two types of neurofibromatosis type 1 gene transcripts in gastric cancers and comparison of GAP activities. Biochem Biophys Res Commun. 1992;187(1):332-9.

28. Andersen LB, Ballester R, Marchuk DA, Chang E, Gutmann DH, Saulino AM Camonis J, Wigler M, Collins FS. A conserved alternative splice in the von Recklinghausen neurofibromatosis (NF1) gene produces two neurofibromin isoforms, both of which have GTPase-activating protein activity. Mol Cell Biol. 1993 Jan;13(1):487-95

29. Riccardi VM. Neurofibromatosis: clinical heterogeneity. Curr Probl Cancer. 1982;7(2):1-34.

30. Pfaffl MW. A new mathematical model for relative quantification in real-time RT-PCR. Nucleic Acids Res. 2001;29(9):e45.

31. Messiaen LM, Callens T, Mortier G, Beysen D, Vandenbroucke I, Van Roy N, Speleman F, Paepe AD. Exhaustive mutation analysis of the NF1 gene allows identification of $95 \%$ of mutations and reveals a high frequency of unusual splicing defects. Hum Mutat. 2000;15(6):541-55.

32. Pros E, Larriba S, López E, Ravella A, Gili ML, Kruyer H, Valls J, Serra E, Lázaro C. NF1 mutation rather than individual genetic variability is the main determinant of the NF1-transcriptional profile of mutations affecting splicing. Hum Mutat. 2006 Nov:27(11):1104-14.

33. Andersen LB, Ballester R, Marchuk DA, Chang E, Gutmann DH, Saulino AM Camonis J, Wigler M, Collins FS. A conserved alternative splice in the von Recklinghausen neurofibromatosis (NF1) gene produces two neurofibromin isoforms, both of which have GTPase-activating protein activity. Mol Cell Biol. 1993 Jan;13(1):487-95.

34. Maertens O, De Schepper S, Vandesompele J, Brems H, Heyns I, Janssens S, Speleman F, Legius E, Messiaen L. Molecular dissection of isolated disease features in mosaic neurofibromatosis type 1. Am J Hum Genet. 2007;81(2): 243-51 Epub 2007 Jun 20

35. Stevenson DA, Zhou H, Ashrafi S, Messiaen LM, Carey JC, D'Astous JL, Santora SD, Viskochil DH. Double inactivation of NF1 in tibial pseudarthrosis. Am J Hum Genet. 2006;79(1):143-8 Epub 2006 May 10.

36. Sant DW, Margraf RL, Stevenson DA, Grossmann AH, Viskochil DH, Hanson $H$, Everitt MD, Rios JJ, Elefteriou F, Hennessey T, Mao R. Evaluation of somatic mutations in tibial pseudarthrosis samples in neurofibromatosis type 1. J Med Genet. 2015;52(4):256-61. https://doi.org/10.1136/jmedgenet2014-102815 Epub 2015 Jan 22

37. Gutmann DH, Ferner RE, Listernick RH, Korf BR, Wolters PL, Johnson KJ. Neurofibromatosis type 1. Nat Rev Dis Primers. 2017 Feb 23;3:17004. https://doi.org/10.1038/nrdp.2017.4. 
38. Porter RS, Jaamour F, Iwase S. Neuron-specific alternative splicing of transcriptional machineries: implications. For neurodevelopmental disorders. Mol Cell Neurosci. 2018 Mar;87:35-45. https://doi.org/10.1016/ j.men.2017.10.006.

39. Lara-Pezzi E, Desco M, Gatto A, Gómez-Gaviro MV. Neurogenesis: regulation by alternative splicing and related posttranscriptional processes. Neuroscientist. 2017 Oct;23(5):466-77. https://doi.org/10.1177/1073858416678604.

40. Song $X$, Zeng Z, Wei $H$, Wang Z. Alternative splicing in cancers: from aberrant regulation to new therapeutics. Semin Cell Dev Biol. 2018;75:13-22. https://doi.org/10.1016/j.semcdb.2017.09.018).

41. Perrone B, La Cognata V, Sprovieri T, Ungaro C, Conforti FL, Andò S, Cavallaro S. Alternative splicing of ALS genes: Misregulation and potential therapies. Mol Neurobiol. 2019 Aug 5. https://doi.org/10.1007/s10571-01900717-0.

42. Black AJ, Gamarra JR, Giudice J. More than a messenger: Alternative splicing as a therapeutic target. Biochim Biophys Acta Gene Regul Mech. 2019.

\section{Publisher's Note}

Springer Nature remains neutral with regard to jurisdictional claims in published maps and institutional affiliations.

Ready to submit your research? Choose BMC and benefit from:

- fast, convenient online submission

- thorough peer review by experienced researchers in your field

- rapid publication on acceptance

- support for research data, including large and complex data types

- gold Open Access which fosters wider collaboration and increased citations

- maximum visibility for your research: over $100 \mathrm{M}$ website views per year

At BMC, research is always in progress.

Learn more biomedcentral.com/submissions 